\section{Eutectic mixture of local anaesthetics is not effective for extra- corporeal shock wave lithotripsy}

Sugantha Ganapathy FRCPC, ${ }^{*}$ Hassan Razvi FRCSC, $\dagger$ Carrol Moote FRCPC, $\ddagger$ John Parkin FRCPC,* Irvan Yee FRCPC,* Sharunas Gverzdys FRCPC,* Steven Dain FRCPC,* John D. Denstedt FRCSC $†$
Purpose: Eutectic mixture of local anaesthetics (EMLA $\left.{ }^{\circledR}\right)$ produces cutaneous analgesia. This randomized, double blind, placebo controlled study evaluated the efficacy of EMLA cream during extracorporeal shock wave lithotripsy (ESWL) using the Dornier ${ }^{\circledR}$ MFL 5000 lithotripter.

Methods: Patients scheduled to undergo lithotripsy of renal or pelviureteric junction stones were randomized to receive either 30 g EMLA cream $(E)$ or placebo $(P)$ over the kidney area 60-90 min before the procedure. During lithotripsy all patients received alfentanil via a PCA machine (dose$10 \mu \cdot \mathrm{kg}^{-1}$, lockout time - three minutes, no basal infusion). Additional bolus doses of $5 \mu \mathrm{g} \cdot \mathrm{kg}^{-1}$ alfentanil were administered by the anaesthetist if analgesia was inadequate. Visual analogue scores (VAS) for pain were documented prior to application of the cream. On arrival in the post anaesthesia care unit VAS pain scores were documented for maximum pain and average pain felt during the procedure as well as for satisfaction of the analgesic technique used. Total time spent in the $P A C U$ and the Aldrete scores on arrival were compared.

Results: Eighty-three patients completed the study. Demographic data were similar between the two groups. Also, VAS for maximal pain, average pain and satisfaction and the total number of shock waves were similar although the EMLA

\section{Key words}

ANAESTHETICS, LOCAL: Eutectic Mixture of Local

Anaesthetics;

ANAESTHETIC TECHNIQUES: patient controlled analgesia DRUGS: opioids, alfentanil;

SURGERY: Extracorporeal Shock Wave Lithotripsy (ESWL).

From the Department of Anaesthesia* and Division of Urology $\dagger$, St. Joseph's Health Centre, and the $\ddagger$ Department of Anaesthesia, University Hospital, The University of Western Ontario, London, Ontario, Canada.

Address correspondence to: Dr. S. Ganapathy, Department of Anesthesia, St. Joseph's Health Centre, P O Box 5777. London, Ontario, Canada, N6A 4L6.

Accepted for publication 18th May, 1996. group received more shock waves at the lower energy level ( $k V)(P<0.0001)$. Total dose of alfentanil, dose as boluses, rate of alfentanil use, total number of PCA attempts and missed attempts were similar. The incidence of adverse events such as bradypnoea, airway obstruction, transient hypoxaemia, pruritus and nausea were small and similar. There was a slightly higher incidence of inadequate analgesia documented by the anaesthetist in the EMLA group. There was no difference between the groups with regards to duration of stay in the PACU, incidence of nausea or Aldrete scores on admission to PACU.

Conclusions: During lithotripsy EMLA cream does not modify the pain perceived nor does it have any opioid sparing effect. It does not facilitate early discharge from the PACU.

Objectif: Le mélange eutectique d'anesthésiques locaux (EMLA $\left.{ }^{\circledR}\right)$ produit de l'analgésie cutanée. Cette étude aléatoire en double aveugle et contrôlée par placebo évaluait la crème EMLA pendant la lithotripsie extracorporelle par ondes de choc réalisée avec un lithotripteur Dornier ${ }^{\circledR}$ MFL 5000.

Méthodes: Des patients programmés pour une lithotripsie de calculs rénaux ou de la jonction pelvi-urétérale ont été répartis au hasard pour recevoir soit $30 \mathrm{~g}$ de crème EMLA $(E)$ ou un placebo $(P)$ sur la peau de la région rénale 60-90 min avant l'intervention. Pendant la lithotripsie, tous les patients recevaient de l'alfentanil par un dispositif de PCA (dose: $10 \mu \mathrm{g} \cdot \mathrm{kg}^{-1}$, intervalle de sécurité trois minutes, perfusion aucune). Des bolus supplémentaires de $5 \mu \mathrm{g} \cdot \mathrm{kg}^{-1}$ d'alfentanil étaient administrés par l'anesthésiste si l'analgésie était insuffisante. Le score sur échelle visuelle analogique (ÉVA) était enregistré avant l'application de la crème. À l'arrivée à l'unité des soins postanesthésiques (USP), on notait les score d'ÉVA pour la douleur maximale et la douleur moyenne perçue pendant l'intervention ainsi que le degré de satisfaction. Le temps total passé à l'USP et les scores sur l'échelle d'Aldrete à l'arrivée étaient comparés.

Résultats: Quatre-vingt-trois patients ont complété l'étude. Les données démographiques étaient identiques pour les deux groupes. L'ÉVA pour la douleur maximale et moyenne était aussi identique ainsi que le nombre total d'ondes de choc bien 
que le groupe EMLA ait reçu plus d'ondes de choc de faible intensité $(k V)(P<0,0001)$. Les doses totale d'alfentanil, le nombre de bolus, la vitesse de perfusion de l'alfentanil, le nombre total de tentatives et de tentatives avortées de PCA étaient identiques. L'incidence des incidents comme la bradypnée, l'obstruction des voies aériennes, d'hypoxémie transitoire, de prurit et de nausées était faible et similaire. L'incidence de l'analgésie inadéquate notée par l'anesthésiste était légèrement plus élevée dans le groupe EMLA. La durée du séjour à L'USP, l'incidence de nausées et les scores sur l'échelle d'Aldrete à l'admission à l'USP ne différaient pas entre les groupes.

Conclusion: Pendant la lithotripsie, la crème EMLA n'a pas modifié la perception de la douleur ni produit un effet d'épargne morphinique. Son application ne pas raccourcit le séjour à l'USP.

Extracorporeal Shock Wave Lithotripsy (ESWL)* represents first-line therapy for the majority of urinary tract calculi. The majority of treatments are performed on an ambulatory basis necessitating a rapid turn over in order to provide cost-effective utilization of the facility. During the procedure patients may experience pain and patient movement during the procedure may necessitate repeated radiographic localization for effective lithotripsy. Effective ESWL requires a cooperative patient who will remain immobile on the lithotripsy table. Profound analgesia with rapid recovery is therefore desirable. Opioid analgesics are commonly used to achieve these goals. Occasionally, discharge is delayed due to persistent sedation and nausea. Analgesic adjuvants may reduce opioid requirements, opioid related side effects and recovery time. It has been documented that EMLA cream reduces the pain of insertion of intravenous lines, ${ }^{1.2}$ epidural needle insertion ${ }^{3}$ as well as tourniquet induced pain. ${ }^{4}$ There are conflicting reports of its efficacy during ESWL. ${ }^{5-9}$ This study attempted to evaluate, in a randomized, double blind, placebo controlled fashion, the efficacy of topical EMLA cream in reducing the opioid requirement during ESWL.

\section{Methods}

After institutional ethics committee approval and written informed consent, 105 patients belonging to American Society of Anesthesiologists' (ASA) physical status I-III, scheduled to undergo elective shock wave lithotripsy of kidney or pelviureteric junction stones were enrolled in this randomized, double blind, placebocontrolled clinical trial. Patients with psychiatric problems, inability to comprehend the English language,

*Dornier Medical Systems, Inc., Kennesaw, Georgia. inability to use the PCA device, a history of chronic opioid use or use in the previous $24 \mathrm{hr}$ or those requiring concurrent ureteral stent placement were excluded from the study.

Patients were randomized to one of two groups. Group E (EMLA) received $30 \mathrm{~g}^{\text {EMLA }^{(B)}}$ cream applied over a $15 \mathrm{~cm} \times 20 \mathrm{~cm}$ area over the intended kidney and covered by an occlusive dressing. Group $P$ (Placebo) received $30 \mathrm{~g}$ placebo with identical consistency and colour applied over the kidney area. Cream application for both groups was performed 60-90 min before the scheduled lithotripsy. Randomization and preparation of the cream was performed by the hospital pharmacy. A preoperative VAS score $(0=$ no pain and $100=$ worst pain) for pain was obtained and patients were instructed with regard to the use of the PCA machine (Bard PCAII). $\dagger$ On arrival in the lithotripsy unit, an intravenous infusion was started with Lactated Ringer's solution. Monitoring included automated noninvasive blood pressure measured every three minutes, pulse oximetry, capnography and continuous electrocardiogram. All patients received supplemental oxygen via a face mask. All patients received either metoclopramide $10 \mathrm{mg}$ or droperidol $1 \mathrm{mg} i v$ as a prophylactic antiemetic. The PCA pump was set to deliver a dose of $10 \mu \mathrm{g} \cdot \mathrm{kg}^{-1}$ with a lockout time of three minutes. No basal infusion was used. If the patient complained of pain or could not lie still due to discomfort, additional doses of alfentanil were administered by the attending anaesthetist at a dose of $5 \mu \mathrm{g} \cdot \mathrm{kg}^{-1}$ as often as required. This step was deemed necessary as the PCA lockout time could not be set at lower than three minutes. No other sedative medications were administered. Inadequate analgesia, nausea, vomiting, pruritus, bradypnoea, airway obstruction, pulse oxygen saturation less than $90 \%$, rigidity and apnoea lasting longer than 20 sec were documented. Shockwave lithotripsy was performed using the Dornier MFL 5000 shockwave lithotripter. This device does not require patient immersion in a water bath, but instead employs a shock tube that is applied directly in contact with the patient's skin. Note was made of the number of shocks administered at each lithotripter energy level $(\mathrm{kV})$ as well as the total number of shocks delivered. The total alfentanil dose, number of successful and unsuccessful attempts were calculated. On arrival in the lithotripsy recovery unit VAS for maximum pain felt during the procedure, average pain felt throughout the procedure and VAS for satisfaction were documented by a blinded nurse. Duration of stay in the PACU, incidence of nausea and vomiting, Aldrete scores on admission to 
PACU and analgesic administration in PACU were noted.

Parametric and nonparametric data were compared using $t$ test and chi square respectively. A $P$ value < 0.05 was considered statistically significant.

\section{Results}

A total of 105 subjects were entered into the study. Twenty two patients (10 in the EMLA group and 12 in the Placebo group) were excluded from the study for the following reasons: PCA equipment malfunction (4), time discrepancy between PCA and Lithotripter printouts (3), cancellation of treatment for nonvisualization of stone (3), unanticipated stent insertion (2), inadequate data collection (2), problems with cream application such as inadequate preoperative interval, leakage or inappropriate location of application (3), anxiety attacks (2), ureteric stone (1), breach of protocol due to inadequate pain control (1) and wrong dose of bolus administered (1). Metoclopramide was used in 36 patients in the EMLA group and 32 patients in the placebo group. Droperidol was used in six patients in the E group and in seven patients in the $P$ group. One anxiety attack was attributed to droperidol.

Demographic data were similar between the two groups (Table I). The interval between the application of cream and the start of lithotripsy was similar for both groups. There was no detectable difference between the groups in any PCA parameter or any measurement of opioid use (Table II). Preoperative VAS pain scores were higher in the placebo group otherwise there were no statistically significant differences between the groups. The higher preoperative VAS pain scores were contributed by 4 patients all of whom had stents inserted at an earlier visit for an obstructing stone. The EMLA group had more shocks at the lower energy level of $17-20 \mathrm{kV}$. The number of shocks at the higher voltage were similar between the two groups (Table III).

Inadequate analgesia was documented in 9/44 patients in the EMLA group and 1/39 patients in the placebo group $(P=0.0125)$. There was one patient in each group who had transient desaturation to $\mathrm{SPO}_{2}<$ $90 \%$. There were nine patients in the EMLA group and 11 in the placebo group who had transient bradypnoea to $<8$ breaths $\cdot \mathrm{min}^{-1}$. This difference was not statistically significant. The incidence of apnoea, nausea and pruritus was similar between the two groups (Table IV). There were no episodes of airway obstruction.

When data from female patients alone were compared, the EMLA group had a larger number of anaesthetist administered boluses, $(\mathrm{E}=1.5 \pm 1.8$ vs $P=0.71$ $\pm 0.27), P=0.008$ larger dose of alfentanil administered by the anaesthetist $(\mathrm{E}=517 \pm 569$ vs $P=25 \pm 93.5), P$ $=0.0039$ and higher rate of alfentanil consumption
TABLE I Demographic data

\begin{tabular}{lccl}
\hline & $\begin{array}{l}\text { EMLA } \\
(n=44)\end{array}$ & $\begin{array}{l}\text { Placebo } \\
(n=39)\end{array}$ & $P$ \\
\hline Age (yr) & $47.1 \pm 11.6$ & $47.4 \pm 12.3$ & 0.9 \\
Male / Female & $32 / 12$ & $25 / 14$ & $0.4^{*}$ \\
Weight (kg) & $73.5 \pm 13.1$ & $74.7 \pm 11.9$ & 0.67 \\
Height (cm) & $170.3 \pm 8.5$ & $167.2 \pm 26.1$ & 0.46 \\
First ESWL / Repeat ESWL & $29 / 12$ & $31 / 5$ & $0.1 \dagger$ \\
ASA 1:2:3 & $27: 13: 2$ & $22: 15: 1$ & 0.6 \\
\hline
\end{tabular}

Data are expressed as mean $\pm \mathrm{SD}$

*Chi squared test.

$\dagger$ No data on six patients.

TABLE II PCA data

\begin{tabular}{lccl}
\hline & $\begin{array}{l}\text { EMLA } \\
(n=44)\end{array}$ & $\begin{array}{l}\text { Placebo } \\
(n=39)\end{array}$ & $P$ \\
\hline Interval (min) & $96.8 \pm 37.5$ & $90.9 \pm 34.7$ & 0.46 \\
PCA duration & $29.0 \pm 7.96$ & $32.8 \pm 10.1$ & 0.06 \\
Dose $(\mu \mathrm{g})$ & $737.5 \pm 133.8$ & $744.9 \pm 118.5$ & 0.79 \\
Patient demand dose $(\mu \mathrm{g})$ & $2763.6 \pm 917.8$ & $3019.2 \pm 1200.8$ & 0.28 \\
Number of anaesthetist & & & \\
$\quad$ administered boluses & $0.578 \pm 1.2$ & $0.2 \pm 0.87$ & 0.14 \\
Dose as boluses ( $\mu \mathrm{g})$ & $200 \pm 384$ & $100.6 \pm 413$ & 0.26 \\
Total dose of alfentanil & & & \\
$\quad(\mu \mathrm{g})$ & $2963.6 \pm 912$ & $3119.9 \pm 1413$ & 0.55 \\
Rate of alfentanil use & & & \\
$\quad\left(\mu \mathrm{g} \cdot \mathrm{kg}^{-1} \cdot\right.$ min $^{-1}$ ) & $1.44 \pm 0.5$ & $1.3 \pm 0.5$ & 0.23 \\
Total attempts & $10.5 \pm 11$ & $7.3 \pm 5.1$ & 0.11 \\
Missed attempts & $6.6 \pm 10.7$ & $3.2 \pm 4.2$ & 0.07 \\
Injections /total attempts & $0.66 \pm 0.7$ & $0.67 \pm 0.24$ & 0.94 \\
VAS pain (preop) & $1.9 \pm 4.2$ & $8.8 \pm 15.8$ & $0.007 *$ \\
VAS (maximal pain) & $34.3 \pm 24.6$ & $38.3 \pm 26.3$ & 0.47 \\
VAS (average pain) & $17.6 \pm 14.5$ & $18.9 \pm 15.4$ & 0.7 \\
VAS (satisfaction) & $85.9 \pm 23.8$ & $88.8 \pm 20.8$ & 0.55 \\
\hline
\end{tabular}

Data are mean \pm SD.

TABLE III Shocks

\begin{tabular}{lccl}
\hline $\begin{array}{l}\text { Energy level } \\
(k V)\end{array}$ & $\begin{array}{l}\text { EMLA } \\
(n=43)\end{array}$ & $\begin{array}{l}\text { Placebo } \\
(n=39)\end{array}$ & $P$ \\
\hline $17-20$ & $354 \pm 323$ & $191.9 \pm 173.8$ & $<0.0001^{*}$ \\
$21-22$ & $541.6 \pm 652$ & $537 \pm 736.5$ & $\mathrm{NS}$ \\
$23-25$ & $1578.5 \pm 1081$ & $1702 \pm 1014.6$ & $\mathrm{NS}$ \\
\hline
\end{tabular}

Data are mean $\pm S D$.

Data from one case was incomplete.

*Statistically significant.

expressed as $\mu \mathrm{g} \cdot \mathrm{kg}^{-1} \cdot \mathrm{min}^{-1}(\mathrm{E}=1.69 \pm 0.38$ vs $P=1.2$ $\pm 0.37), P=0.0021$. The VAS for satisfaction was also lower in the EMLA group $(\mathrm{E}=73.7 \pm 32.2$ vs $P=93.7$ $\pm 10.7), P=0.04$

When data from male patients were compared there were no differences between the EMLA and placebo groups except with respect to preoperative VAS for 
TABLE IV Complications

\begin{tabular}{llcl}
\hline & $\begin{array}{l}\text { EMLA } \\
(n=44)\end{array}$ & $\begin{array}{l}\text { Placebo } \\
(n=39)\end{array}$ & $P$ \\
\hline $\mathrm{SpO}_{2}<90 \%$ & 1 & 1 & 0.93 \\
${\text { Bradypnoea }<8 \cdot \mathrm{min}^{-1}}_{\text {Apnoea }>20 \mathrm{sec}}$ & 9 & 11 & 0.41 \\
Airway obstruction & 5 & 5 & 0.84 \\
Inadequate analgesia & 0 & 0 & - \\
Nausea & 9 & 1 & 0.0125 \\
Pruritus & 3 & 2 & 0.75 \\
\hline
\end{tabular}

Chi square test $P<0.05$.

pain. There were four male patients in the placebo group who had scored $>30$ on the preoperative VAS pain score. All four had an obstructing stone necessitating previous insertion of an ureteral stent. When we eliminated the data from these patients there were still no differences between the groups with respect to the outcome measures including intraoperative pain scores and alfentanil consumption. Duration of stay in the PACU was similar between the two groups $(E=78.8 \mathrm{~min} \pm 30.9$ vs $P=80.9 \pm 32.4$ ). Admission scores in PACU, incidence of nausea and requirements for analgesia in PACU were also similar between the groups.

Calculation based on the total dose of alfentanil revealed that this study had $95 \%$ power to detect $30 \%$ reduction in alfentanil dose with an alpha error of 0.05 .

\section{Discussion}

Extracorporeal Shock Wave Lithotripsy (ESWL) is now considered the treatment of first choice for the majority of urinary tract calculi. Whether the pain perceived is due to cutaneous or deeper visceral afferent stimulation is unknown. Pain during lithotripsy is reportedly due to cavitation mediated stimulation of nerve fibres. ${ }^{10}$ Although postoperative discomfort following ESWL is considerably less than with operative techniques of stone management, pain during ESWL can be intense. The intensity of pain perceived depends on the energy level of shock waves passing through the tissues. Second generation lithotripters are reported to produce less pain. A variety of anaesthetic techniques has been employed during ESWL including epidural, local infiltration, intercostal block, general anaesthesia and conscious sedation.

EMLA cream has been used to produce cutaneous analgesia during a variety of procedures. ${ }^{13}$ Loening et $a l .,{ }^{11}$ in 1987, reported the efficacy of local infiltration with lidocaine for ESWL suggesting there was a cutaneous component to the pain induced by the lithotripter. Bierkens et al. ${ }^{5}$ reported reduced opioid requirement when EMLA cream was used as a supplement during lithotripsy in a second generation lithotripter. Lichten- berg et al. ${ }^{6}$ in 1992 compared the efficacy of topical EMLA cream with local infiltration with lidocaine $1 \%$ when lithotripsy was performed using the Siemen's Lithostar device. They noted that EMLA was as efficacious as subcutaneous infiltration with lidocaine, but $>70 \%$ of their patients in both groups required analgesic supplements. Tiselius ${ }^{7}$ compared the efficacy of EMLA cream with placebo for lithotripsy using an unmodified Dornier HM3 lithotripter. He noted that at lower voltage $(14 \mathrm{kV})$ more patients in the EMLA group could complete the treatment with morphine and diazepam premedication alone. Fifty percent of their patients in both groups, however, required analgesic supplements even though their maximal median energy setting was only $15.9 \mathrm{kV}$. He concluded that although EMLA could not replace the need for analgesic and sedation, it could be used advantageously to reduce the dosage of analgesic and sedative drugs during lithotripsy.

McDonald et al. ${ }^{8}$ could not confirm these findings using the Storz Modulith SL20: Their figures reveal that some of the higher doses of fentanyl were required only in the patients in the EMLA group. Similarly, Monk et $a l .{ }^{9}$ found EMLA to be ineffective in reducing opioid requirements during immersion lithotripsy using an unmodified Dornier HM3 lithotripter.

In our current study we used PCA to deliver the alfentanil according to patient requirements supplemented by anaesthetist administered boluses. The lockout period with our PCA device (Bard PCAII) cannot be reduced below three minutes and in our earlier experience we noted that these patients were very uncomfortable especially at the beginning of lithotripsy even at the lowest energy levels. We omitted administration of amnesic agents since all of our pain scores were reported on arrival in the recovery room.

There were several logistical problems encountered with the use of EMLA. Our patients report to the hospital approximately $90-120 \mathrm{~min}$ before the scheduled time of lithotripsy. Many of the patients are referrals from peripheral hospitals and, therefore, need evaluation on arrival including radiographic imaging. This delays application of the cream. Cream application must be placed precisely in order to be effective. We had to eliminate one patient as the cream was not applied in the appropriate location.

There were no patients in this study population who did not demand and get alfentanil via the PCA device. We could not find any difference between the groups with regards to intraoperative painscores or use of opioids. The preoperative VAS for pain was higher in the placebo group which was influenced by four men in this group who scored $>30$ out of 100 . When we eliminated the data from these patients we could not find any difference between the groups. The higher number of 
shocks at the lower energy level in the EMLA group biases the results in favour of EMLA since lower energy shocks are less painful. ${ }^{12}$

Our usual routine is to begin lithotripsy at the lowest energy level $(17 \mathrm{kV})$ and gradually increase the energy level during the procedure. We noted that the most discomfort, however, was at the start of lithotripsy. Patients' discomfort usually settled after the first few boluses of alfentanil. Use of lower levels of energy (kV) will prolong the duration of time required to fragment the stones as well as increase the probability of unsuccessful lithotripsy.

Analysis of data from men alone revealed no difference between the two groups. Data from females on the other hand, demonstrated that the EMLA group received twice as many anaesthetist-administered boluses, higher doses of anaesthetist administered boluses, a higher rate of consumption of alfentanil and a lower satisfaction score. These differences were statistically significant. Unfortunately the number of female patients was too small to draw any conclusions with confidence.

A variety of factors may influence the absorption and clearance of EMLA cream from the skin. These include skin blood flow, dermal and epidermal thickness, duration of application and pigmentation. Longer application has been documented to produce erythema probably due to vasodilatation. ${ }^{13}$ This could lead to rapid clearance of the drug from the skin resulting in inadequate analgesia. This is evidenced by decreased analgesic efficacy with increasing application time when EMLA is used on the forehead which has four to five times the cutaneous blood flow of other areas such as the dorsum of hand and antecubital fossa.

The cost of $30 \mathrm{~g}$ EMLA is $\$ 27$ in Canada and this additional cost along with the cost of occlusive dressing and nursing time should not be added to the cost of patient care unless the application contributes towards improved patient management. Neither patient comfort nor the duration of stay in the post anaesthesia care unit were favourably altered by the application of EMLA cream.

Our study demonstrated that EMLA is not effective in reducing the pain of lithotripsy using the Dornier MFL 5000 lithotripter. It does not reduce the opioid requirement at the energy level of shock waves commonly used during ESWL. This finding suggests that the major component of the pain of lithotripsy arises from deeper visceral structures rather than from the skin. The rapid turnover required of this service as well as the high cost of the drug are additional limiting factors with the use of EMLA for lithotripsy. Based on our results we cannot recommend the use of EMLA cream for shock wave lithotripsy.

\section{Acknowledgements}

The authors wish to gratefully acknowledge the assistance of the nurses from the St. Joseph's Health Centre lithotripsy day care unit.

\section{References}

1 Hallén B, Carlsson P, Uppfeldt A. Clinical study of lidocaine-prilocaine cream to relieve the pain of venepuncture. Br J Anaesth 1985; 57: 326-8.

2 Wehle $B$, Björnström $M$, Cedgård $M$, et al. Repeated application of EMLA cream 5\% for the alleviation of cannulation pain in haemodialysis. Scand J Urol Nephrol 1989; 23: 299-302.

3 Ralston SJ, Head-Rapson AG. Use of EMLA cream for skin anaesthesia prior to epidural insertion in labour. Anaesthesia 1993; 48: 65-7.

4 Lowrie A, Jones MJ, Eastley RJ. Effect of a eutectic mixture of local anaesthetic agents (EMLA) on tourniquet pain in volunteers. Br J Anaesth 1989; 63: 751-3.

5 Bierkens AF, Maes RM, Hendrikx AJM, Erdos AF, de Vries $J D M$, Debruyne FMJ. The use of local anesthesia in second generation extracorporeal shock wave lithotripsy: eutectic mixture of local anaesthetics. J Urol 1991; 146: 287-9.

6 De Lichtenberg MH, Miskowiak J, Mogensen P, Andersen $J T$. Local anesthesia for extracorporeal shock wave lithotripsy: a study comparing eutetic mixture of local anesthetics cream and lidocaine infiltration. J Urol 1992; 147: 96-7.

7 Tiselius $H-G$. Cutaneous anesthesia with lidocaine-prilocaine cream: a useful adjunct during shock wave lithotripsy with analgesic sedation. J Urol 1993; 149: 8-11.

8 McDonald PF, Berry AM. Topical anaesthesia for extracorporeal shock wave lithotripsy. Br J Anaesth 1992; 69 : 399-400.

9 Monk TG, Ding Y, White PF, Albala DM, Clayman RV. Effect of topical eutectic mixture of local anesthetics on pain response and analgesic requirement during lithotripsy procedures. Anesth Analg 1994; 79: 506-11.

10 Schelling $G$, Delius $M$, Gschwender M, Grafe P, Gambihler $S$. Pain during shock wave lithotripsy is not a direct shock wave effect but results from cavitation mediated stimulation of nerve fibers. Anesthesiology 1993; 79: A824.

11 Loening S, Kramolowsky EV, Willoughby B. Use of local anesthesia for extracorporeal shock wave lithotripsy. $J$ Urol 1987; 137: 626-8.

12 Bromage $P R$. Effect of topical eutectic mixture of local anesthetics on pain response and analgesic requirement during extracorporeal shock wave lithotripsy (Letter). Anesth Analg 1995; 80: 1059.

13 Gajraj NM, Pennant $J H$, Watcha $M F$. Eutectic mixture of local anesthetics (EMLA ${ }^{\circledR}$ ) cream. Anesth Analg 1994; 78: 574-83. 